\title{
As políticas sociais públicas e os novos sujeitos de direitos: crianças e adolescentes
}

\author{
Jimena Cristina Gomes Aranda Oliva \\ Pontifícia Universidade Católica do Paraná (PUC-PR)
}

\author{
Samira Kauchakje \\ Pontifícia Universidade Católica do Paraná (PUC-PR)
}

\begin{abstract}
As políticas sociais públicas e os novos sujeitos de direitos: crianças e adolescentes
Resumo: Este artigo apresenta uma pesquisa sobre direitos de crianças e adolescentes com foco em sua efetivação pelas políticas de saúde, educação, assistência social e criança e adolescente nas capitais brasileiras. O objetivo foi analisar ações públicas entre 2004 e 2007 à luz do Estatuto da Criança e do Adolescente (ECA). A pesquisa documental coletou dados nos Planos Plurianuais Municipais, considerando as características e os objetivos das ações e dos equipamentos ofertados às crianças, aos adolescentes e às suas famílias. As informações foram sistematizadas e analisadas, mobilizando a base conceitual e histórica sobre o tema. Os resultados apontaram a heterogeneidade de ações entre as capitais, indicaram os municípios mais próximos da previsão legal e revelaram ser a educação a política pública com maior número de ações. Registra-se nas conclusões que, a despeito do marco legal, a prioridade nas políticas públicas para as crianças, os adolescentes e suas famílias não está expressa nos documentos pesquisados.

Palavras-chave: criança, adolescente, lutas sociais.
\end{abstract}

\section{Government Social Policies and the New Subjects of Laws: Children and Adolescents}

Abstract: This article presents a study about the rights of children and adolescents. It focuses on their application in healthcare, education, social assistance and children and adolescents policies in Brazilian capitals. The objective was to analyze public policies from $2004-2007$ considering the federal Statute for Children and Adolescents. The document research collected data from the municipal Pluriannual Plans, considering the characteristics and objectives of the actions and the facilities offered to children, adolescents and their families. The information was systematized and analyzed, mobilizing the conceptual and historic base of the issue. The results reveal the heterogeneity of the actions among the state capitals, indicate those municipalities which come closest to meeting the legal forecast and show that education is the public policy with the greatest number of actions. The paper concludes that despite the legal foundation, a priority in public policies for children, adolescents and their families are not expressed in the documents studied.

Key words: children, adolescents, social struggles. 


\section{Introdução}

A Constituição Federal de 1988 e a Lei n. 8.069 de 13 de julho de 1990 (BRASIL, 1995, 1999), denominada Estatuto da Criança e do Adolescente (ECA), trouxeram inúmeras inovações na área de políticas públicas dirigidas a esse segmento; consideraram a infância e a juventude como prioridade absoluta, merecedoras de proteção integral por parte da família, da sociedade e do Estado; consideraram crianças e adolescentes como pessoas em condição peculiar de desenvolvimento e merecedores de proteção especial.

A mudança nesse modo de sentir e pensar o mundo infanto-juvenil deve-se a um novo sistema que está sendo construído para o século 21: o sistema de Proteção Integral. Nele se quer a proteção de meninos e meninas não em instituições, mas no sistema multiparticipativo e aberto da cidadania social, cujos sujeitos são anciãos, adultos, adolescentes e crianças (SEDA,1995).

A nova forma de tratamento à infância e à juventude baseia-se numa rede de atendimento envolvendo Conselhos de Direitos da Criança e do Adolescente, Conselhos Tutelares, Ministério Público, Varas da Infância e Juventude, Delegacias de Defesa da Criança e do Adolescente, Organizações Não Governamentais. E, ainda, por políticas integradas por: programas, ações, projetos, que deverão atuar conjuntamente com a finalidade de garantir que sejam cumpridas as necessidades previstas na Constituição Federal e no ECA, em benefício das crianças e adolescentes e que sejam capazes de garantir-lhes plenas condições de desenvolvimento pessoal.

A fim de verificar se os princípios contidos na lei estão sendo colocados em prática nas cidades, foi realizada uma pesquisa documental, envolvendo 19 capitais brasileiras e seus respectivos planos plurianuais, examinando se a priorização determinada pela legislação se reflete no planejamento dos gestores de grandes municípios brasileiros.

$\mathrm{O}$ presente artigo está dividido em quatro partes: a primeira versa sobre crianças e adolescentes como novos sujeitos direitos no ordenamento jurídico brasileiro, analisando para isso os marcos legais. A segunda parte descreve a metodologia da pesqui$\mathrm{sa}$, enquanto a terceira trata de políticas, programas e projetos destinados à infância e juventude e a gestão municipal. A quarta e última parte demonstra os dados da pesquisa sobre as ações sociais para a infância e juventude em 19 capitais brasileiras, analisando e cotejando os resultados encontrados, seus instrumentos de gestão, as ações, políticas e projetos desenvolvidos com o referencial teórico inicialmente apresentado.

\section{O ECA, a Constituição Federal e os novos sujeitos de direito}

Historicamente, crianças e adolescentes vêm sendo vistos e tratados de forma desrespeitosa levandose em conta os parâmetros atuais que os consideram pessoas em condição peculiar de desenvolvimento, dignos de respeito e reconhecidos em sua plena cidadania. De acordo com os valores e costumes atuais, não mais se admite que crianças e adolescentes sejam vítimas de violência, negligência e opressão, porém, de acordo com o momento histórico observado e a cultura local, esse paradigma pode modificar-se.

A começar pela História da Antiguidade, em Roma o poder paterno era supervalorizado de forma que o pai tinha todo o poder sobre o filho, tendo direito de transferi-lo a terceiro (por doação ou penhora), escravizá-lo e até de matá-lo. Sobre esse importante período histórico: "Durante o tempo de Augusto os recém-nascidos eram expostos nas portas do palácio imperial, matando-se os não eleitos, prática que cumpria as funções atuais do aborto"(MENDEZ, 1991, p. 47).

$\mathrm{Na}$ Idade Média, período marcado entre séculos 5 e 15, a figura da criança se torna invisível e irrelevante à sociedade. Dentro desse paradigma, novos rumos traçam-se às crianças e aos adolescentes, que num primeiro momento foram reduzidos de pouca presença à exclusão social (VERONESE; RODRIGUES, 2001).

Os séculos 15 e 16 trouxeram o reordenamento familiar e a constituição de novas relações afetivas entre os familiares, devido a uma preocupação com a higiene e a saúde física da criança, buscando evitar a sua morte (MAGALHÃES; BARBOSA, 2005).

No Brasil, o tratamento destinado às crianças e aos jovens não foi diferente. Essa situação só encontrou grandes modificações no final da década de 1980, com o fim da ditadura militar e um grande movimento envolvendo a sociedade civil organizada na mobilização pelo reconhecimento dos direitos da criança e do adolescente, reflexo de um movimento internacional (PIOVESAN, 2004).

Pontes Junior (1993) afirma que as crianças e os adolescentes são sujeitos de direitos universalmente reconhecidos, não apenas de direitos comuns aos adultos, mas além desses. São detentores de direitos especiais, provenientes de sua condição peculiar de pessoas em desenvolvimento.

A afirmação dos direitos da criança e do adolescente pela comunidade internacional se consolida com a adoção pela $\mathrm{ONU}$, em Assembleia Geral realizada em 20 de novembro de 1989, da Convenção dos Direitos da Criança, ratificada pelo Brasil e pela quase totalidade dos países hoje existentes no mundo (SANTOS, 2006).

A partir da Constituição de 1988, ela mesma resultado da luta dos movimentos da sociedade, grupos organizados em torno da questão da criança e do adolescente e de problemas mais gerais, ligados ao 
direito e à redemocratização do Estado, introduzem uma outra concepção de proteção social. Concepção que pressupõe o desenvolvimento de políticas universais e integradas, estruturadas sob o princípio de uma gestão pública participativa.

Após a Constituição de 1988, os municípios deixaram de ser unidades meramente administrativas e assumiram, ao lado dos Estados, novas atribuições, adquirindo maior autonomia e poder de decisão (DOWBOR, 2006). A Constituição e o Estatuto limitam as ações a cargo direto da União, restringem o papel dos Estados e ampliam de forma considerável as competências e responsabilidades do município e da comunidade organizada. Assim, cabe a coordenação e as normas gerais à esfera federal, a coordenação e a execução às esferas estadual e municipal (COSTA, 2001)

O município tem a perspectiva no novo ordenamento de se auto-organizar por meio da participação da sociedade civil, numa tentativa de enfrentamento à problemática social constatada na infância e na juventude.

\section{Metodologia}

A pesquisa é de tipo quantitativa e qualitativa, com coleta de dados em documentos - Planos Plurianuais Municipais (PPA) referentes ao quadriênio 2004-2007. A pesquisa é também em grande parte telematizada, a partir dos documentos disponibilizados em sítios da internet. Do total das 27 capitais brasileiras, conseguiu-se acesso via internet aos PPAs de 19 que compuseram o universo da pesquisa. São elas, por região:

a) Região Norte: Belém, Boa Vista, Palmas, Porto Velho e Rio Branco;

b) Região Nordeste: Aracaju, João Pessoa, Natal, Recife, Salvador e São Luís;

c) Região Centro-Oeste: Brasília e Goiânia;

d) Região Sudeste: Belo Horizonte, Rio de Janeiro, São Paulo e Vitória;

e) Região Sul: Curitiba e Porto Alegre.

Para subsidiar as discussões teóricas, as estratégias metodológicas e a análise das informações, foi realizado um estudo de publicações sobre direitos da infância e juventude, com prioridade para textos clássicos e artigos com credibilidade acadêmico-científica, além da legislação pertinente sobre o tema.

A opção pelo PPA deve-se ao fato que este documento é um instrumento de gestão obrigatório que deve expressar o planejamento das ações e intenções da administração municipal em relação às diversas políticas, entre elas as direcionadas à infância e juventude.

A eleição das capitais brasileiras como base territorial deveu-se à inviabilidade de pesquisar em todos os municípios e por serem as capitais consideradas municípios-referência em cada um dos estados, influenciando e proliferando suas práticas. Além disso, possibilitam apreender a diversidade do país em seus desafios diferenciados de acordo com a localização geográfica, demografia, as características históricas, culturais e a capacidade de gestão.

O estudo dos PPAs buscou estabelecer um comparativo entre as finalidades expressas no ordenamento jurídico com o que realmente está indicado nos documentos sob análise. Após a leitura dos documentos de PPA, foram destacados itens que, de alguma forma, faziam referência a políticas, objetivos, metas, programas e projetos voltados à infância, juventude e famílias. Como muitos programas, projetos e ações são apresentados no PPA com um nome simbólico ou nome fantasia - que por si só não traduzem sua natureza, público-alvo, objetivos -, foi necessário buscar no sítio de cada prefeitura, em periódicos da região e em buscadores da internet, as definições necessárias à classificação e ao entendimento do texto mencionado.

Verificou-se no decorrer da pesquisa grande volume e dispersão de informações que precisaram ser condensadas e sistematizadas. O trabalho de registro foi seguido de categorização e interpretação de acordo com sugestões do método de análise de conteúdo tendo em vista os objetivos desta pesquisa.

A pesquisa teve como objetivos centrais: compreender o Sistema de Garantias de Direitos previsto no ECA e as atribuições estabelecidas entre governo federal, governo estadual e municipal; identificar nas capitais brasileiras as ações sociais desenvolvidas para o PPA 2004-2007, destinadas à infanto-adolescência e suas famílias em situação de risco; perceber as relações, congruências e lacunas em termos de ações, programas, projetos e estruturas necessários à implantação do ECA: os efetivamente mencionados nos documentos de PPA - Plano Plurianual divulgados nos municípios relacionados

Para a sistematização dos dados, foram confeccionados quadros e tabelas para cada capital estudada. Para a análise dos resultados, foi realizado o esforço de atribuição de significado às informações, a partir da base conceitual e histórica sobre o tema, seguindo as sugestões da metodologia da análise de conteúdo e da discussão sobre hermenêutica e dialética de Minayo (1993). Para a autora, enquanto a hermenêutica busca a compreensão, a dialética estabelece uma atitude crítica. Reafirma-se que não houve a intenção de aplicação destas metodologias, mas sim considerar suas contribuições para o trabalho analítico.

\section{Políticas, programas e projetos}

Kauchakje (2007) conceitua as políticas públicas como formas de aplicação dos artigos constitucionais e das leis que os regulamentam, afirmando também que a lei estabelece os objetivos da política, os instru- 
mentos institucionais de sua realização e outras condições de implementação. São instrumentos de ação do governo a serem desenvolvidas em programas, projetos e serviços que são do interesse da sociedade. As políticas podem ser consideradas como desenho/arquitetura planificada dos direitos garantidos em lei.

Entendem-se os programas como as atividades que são oferecidas em bases contínuas, sendo um conjunto de projetos e iniciativas que se articulam e se complementam com vistas à obtenção de resultados assertivos num tempo definido (LOBATO, 2005; KAUCHAKJE, 2007). Para o enfrentamento dos problemas sociais locais, o administrador deverá utilizar-se de técnicas de planejamento. O termo "planejamento", na perspectiva lógico-racional, refere-se ao processo permanente e metódico de abordagem racional e científica de questões que se colocam no mundo social (BAPTISTA, 2003).

A questão do planejamento no setor público mereceu dos constituintes de 1988 uma atenção muito especial, na medida em que foram introduzidos na nova Carta dispositivos com o objetivo de institucionalizar e consolidar a sua prática em todas as esferas de governo - União, estados e municípios. No capítulo dedicado às finanças públicas, foram definidos três instrumentos, distintos, mas interligados entre si: Plano
Plurianual (PPA) Diretrizes Orçamentárias (LDO) e Orçamento Anual (LOA) (REZENDE, 2006).

\section{Discussão dos resultados}

As principais informações foram sistematizadas e discutidas conforme as tabelas a seguir. A tabela $\mathbf{1}$ indica os objetivos apresentados nos PPAs das capitais das quatro regiões, divididos nas áreas da assistência social, educação, saúde e criança e adolescente:

Os objetivos apresentados concentram-se, primeiramente, na política da educação. Em segundo lugar, estão em maior número os objetivos voltados à proteção especial de crianças e adolescentes, em terceiro, as políticas de assistência social e em último, as de saúde. O destaque da política de assistência social, centralizada em poucos objetivos, pode ser explicado pela concentração das suas ações no Sistema Único da Assistência Social (SUAS) que, citado uma única vez, daria conta de um leque diversificado e complexo de ações na área da referida política.

A política da educação aparece privilegiada, é citada por diversas vezes e em diversas modalidades diferentes (educação infantil, ensino fundamental, ensino médio, educação de jovens e adultos, cursinhos pré-

\section{Tabela 1 - Objetivos e políticas setoriais nos PPAs das regiões brasileiras}

\begin{tabular}{|c|c|c|c|c|c|c|c|c|c|c|c|c|c|c|c|c|c|c|}
\hline Região & \multicolumn{5}{|c|}{ Norte } & \multicolumn{5}{|c|}{ Nordeste } & \multicolumn{2}{|c|}{$\begin{array}{l}\text { Centro- } \\
\text { Oeste }\end{array}$} & \multicolumn{4}{|c|}{ Sudeste } & Sul & \multirow{2}{*}{$\begin{array}{l}\mathbf{T} \\
\mathrm{T}\end{array}$} \\
\hline Capital & B & $\begin{array}{l}\mathrm{B} \\
\mathrm{V}\end{array}$ & $\mathrm{P}$ & $\begin{array}{l}\mathrm{P} \\
\mathrm{V}\end{array}$ & $\begin{array}{l}\mathrm{R} \\
\mathrm{B}\end{array}$ & A & $\begin{array}{l}J \\
P\end{array}$ & $\mathrm{~N} \quad \mathrm{R}$ & S & $\begin{array}{l}S \\
L\end{array}$ & $\mathrm{Br}$ & $\mathrm{G}$ & $\begin{array}{l}\text { B } \\
\mathrm{H}\end{array}$ & $\begin{array}{c}\mathrm{R} \\
\mathrm{J}\end{array}$ & $\begin{array}{l}\mathrm{S} \\
\mathrm{P}\end{array}$ & $\mathrm{V}$ & $\begin{array}{ll}\mathrm{C} & \mathrm{P} \\
& \mathrm{A}\end{array}$ & \\
\hline $\begin{array}{l}\text { Assistência } \\
\text { Social }\end{array}$ & 5 & 1 & 0 & 1 & 0 & 2 & 0 & $0 \quad 4$ & 3 & 0 & 2 & 1 & 3 & 1 & 1 & 2 & 10 & 27 \\
\hline Total por região & & & 7 & & & & & 9 & & & & & & 7 & & & 1 & \\
\hline Educação & 13 & 0 & 0 & 1 & 0 & 0 & 2 & 26 & 9 & 0 & 6 & 4 & 11 & 4 & 4 & 5 & 270 & 94 \\
\hline Total por região & & & 14 & & & & & 19 & & & & $\mathbf{0}$ & & & 4 & & 27 & \\
\hline Saúde & 1 & 1 & 1 & 1 & 0 & 0 & 3 & $\begin{array}{ll}3 & 1\end{array}$ & 3 & 0 & 1 & & 1 & 0 & 3 & 0 & $0 \quad 5$ & 35 \\
\hline Total por região & & & 4 & & & & & 10 & & & & 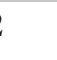 & & 4 & & & 5 & \\
\hline $\begin{array}{c}\text { Criança e } \\
\text { Adolescente }\end{array}$ & 0 & 0 & 1 & 3 & 0 & 3 & 0 & 22 & 3 & 0 & 8 & 0 & 0 & 3 & 1 & 3 & 110 & 40 \\
\hline Total por região & & & 4 & & & & & 10 & & & & 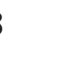 & & 7 & & & 11 & \\
\hline TOTAL & 31 & 1 & 1 & 6 & $\mathbf{0}$ & 7 & 5 & 1116 & 9 & 6 & 7 & 13 & 8 & 8 & 10 & 32 & 125 & 188 \\
\hline
\end{tabular}

Legenda: Região Norte: B: Belém; BV: Boa Vista; P: Palmas; PV: Porto Velho; RB: Rio Branco. Região Nordeste:A: Aracajú; JP: João Pessoa; N:Natal; R: Recife; S: Salvador; SL: São Luís. Região Centro-Oeste: Br:Brasília; G: Goiânia. Região Sudeste: BH:BeloHorizonte; RJ: Rio de Janeiro; SP: São Paulo; V: Vitória. Região Sul: C: Curitiba; PA: PortoAlegre. T: Total .

Fonte: elaboração das autoras. 
vestibulares, ensino profissionalizante). Já os objetivos voltados à saúde da criança, adolescente e famílias aparecem em maior número na Região Nordeste e aqueles voltados à criança e ao adolescente (proteção especial) surgem em maior número na Região Sul do país.

Fazendo-se a análise por capital, em primeiro lugar, infere-se que a política de educação continua a aparecer com maior frequência. A capital com maior destaque é o município de Curitiba, que chega a citar 27 objetivos voltados à educação, em seguida surgem os municípios de Belém (13 citações) e Belo Horizonte (11 citações); já os municípios que deixam de citar qualquer objetivo no PPA voltado à educação são: Boa Vista, Palmas, São Luís e Porto Alegre. A valorização da política da educação e sua implementação para acesso universal se faz mister. Segundo Macedo (2008), uma escolarização deficiente, quando não mesmo inexistente, produzirá profissionais desqualificados a ingressar no competitivo mercado de trabalho, fazendo com que os indivíduos "inaptos" busquem colocação no mercado informal, gerador de baixa renda e baixos índices de seguridade social.

No que se refere à segunda política mais mencionada (proteção especial à criança e ao adolescente), $\mathrm{a}$ capital paranaense também se destaca com 11 objetivos voltados a essa área, em seguida, a capital federal também apresenta muitas intenções de metas voltadas à infância e juventude com 8 itens. As demais capitais não apresentam grandes concentrações de objetivos voltados à infanto-adolescência, sendo que muitas sequer mencionaram objetivos voltados à área (Belém, Boa Vista, Rio Branco, João Pessoa, São Luís, Goiânia, Belo Horizonte e Porto Alegre).

A política de assistência social surge como objetivo mais citado no município de Belém (cinco vezes) e pouco citado (em média uma, duas ou três vezes no máximo). Outras capitais não mencionam a política (Palmas, Rio Branco, João Pessoa, Natal, São Luís e Porto Alegre). Por derradeiro, os objetivos voltados à política de saúde são os menos mencionados, e quando surgem, aparecem em maior quantidade na capital gaúcha.

No que se refere às ações, tabela 2 , em primeiro lugar, quantitativamente, estão as voltadas à educação, 89 vezes, mencionadas, e em maior número na Região Nordeste, 38 vezes, e na Região Norte, 21 vezes. Em segundo lugar, citam-se ações de proteção especial à criança e ao adolescente, mencionadas 76 vezes; em maior número de vezes nas Regiões Norte, 22 vezes, Sul e Nordeste, 20 vezes. Em

\section{Tabela 2- Ações e políticas setoriais nos PPAs das regiões e capitais brasileiras}

\begin{tabular}{|c|c|c|c|c|c|c|c|c|c|c|c|c|c|c|c|c|c|c|c|c|}
\hline Região & \multicolumn{5}{|c|}{ Norte } & \multicolumn{6}{|c|}{ Nordeste } & \multicolumn{2}{|c|}{$\begin{array}{c}\text { Centro- } \\
\text { Oeste }\end{array}$} & \multicolumn{4}{|c|}{ Sudeste } & \multicolumn{2}{|l|}{ Sul } & \multirow{2}{*}{$\begin{array}{l}\mathbf{T} \\
\mathrm{T}\end{array}$} \\
\hline Capital & B & $\begin{array}{l}\mathrm{B} \\
\mathrm{V}\end{array}$ & $\mathrm{P}$ & $\begin{array}{l}\mathrm{P} \\
\mathrm{V}\end{array}$ & $\begin{array}{l}\mathrm{R} \\
\mathrm{B}\end{array}$ & A & $\begin{array}{l}\mathrm{J} \\
\mathrm{P}\end{array}$ & $\mathrm{N}$ & $\mathrm{R}$ & $\mathrm{S}$ & $\begin{array}{l}\mathrm{S} \\
\mathrm{L}\end{array}$ & $\mathrm{Br}$ & G & $\begin{array}{l}\mathrm{B} \\
\mathrm{H}\end{array}$ & $\begin{array}{c}\mathrm{R} \\
\mathrm{J}\end{array}$ & $\begin{array}{l}\mathrm{S} \\
\mathrm{P}\end{array}$ & V & & $\begin{array}{l}\mathrm{P} \\
\mathrm{A}\end{array}$ & \\
\hline $\begin{array}{l}\text { Assistência } \\
\text { Social }\end{array}$ & 1 & 1 & 3 & 0 & 0 & 2 & 0 & 1 & 1 & 0 & 0 & 3 & 2 & 1 & 3 & 3 & 3 & 3 & 3 & 30 \\
\hline Total por região & & & 5 & & & & & & 4 & & & & ; & & & & & 6 & & \\
\hline Educação & 3 & 5 & 12 & 1 & 0 & 7 & 10 & 11 & 1 & 0 & 3 & 7 & 3 & 1 & 2 & 8 & 0 & & 7 & 89 \\
\hline Total por região & & & 21 & & & & & & 8 & & & & 0 & & & & & 9 & & \\
\hline Saúde & 0 & 0 & 0 & 0 & 0 & 0 & 5 & 0 & 0 & 1 & 0 & 2 & & 0 & & 1 & 0 & 4 & 7 & 22 \\
\hline Total por região & & & $\mathbf{0}$ & & & & & & 5 & & & 3 & & & 2 & & & 11 & & \\
\hline $\begin{array}{c}\text { Criançae } \\
\text { Adolescente }\end{array}$ & 3 & 6 & 13 & 0 & 0 & 6 & 3 & 3 & 1 & 6 & 1 & 9 & 1 & 0 & 3 & 0 & 1 & 6 & & 76 \\
\hline Total por região & & & 22 & & & & & & 0 & & & & 0 & & & 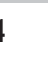 & & 20 & & \\
\hline TOTAL & 7 & 12 & 28 & 1 & 0 & 15 & 18 & 15 & 3 & 13 & 4 & 21 & 7 & 2 & 9 & 12 & 4 & 15 & 31 & 160 \\
\hline
\end{tabular}

Legenda: Região Norte: B: Belém; BV: Boa Vista; P: Palmas; PV: Porto Velho; RB: Rio Branco. Região Nordeste: A: Aracajú; JP: João Pessoa; N: Natal; R: Recife; S: Salvador; SL: São Luís. Região Centro-Oeste: Br: Brasília; G: Goiânia. Região Sudeste:BH:BeloHorizonte; RJ: Rio de Janeiro; SP: São Paulo; V: Vitória. Região Sul: C: Curitiba; PA: Porto Alegre. T: Total .

Fonte: elaboração das autoras. 
terceiro lugar, aparecem as ações voltadas à assistência social, 30 vezes citadas, a maioria é mencionada nos PPAs das capitais do sudeste, 10 vezes. Por derradeiro, são mencionadas quantitativamente as ações voltadas à saúde de crianças e adolescentes, bem como suas famílias (assistência maternoinfantil), com 22 ocorrências, por 12 vezes citadas nos PPAs da Região Sul e nenhuma vez nos PPAs da Região Norte.

Percebe-se que, embora a região em destaque, com mais ações voltadas à educação tenha sido a Região Nordeste, a capital que mais menciona a política é uma capital da Região Norte, Palmas. A segunda capital a citar maior número de ações é Natal, município vinculado à Região Nordeste. Em que pese o número de ações destacadas em capitais e regiões, depreende-se que a educação ainda não alcança todas as crianças e todos os adolescentes, uma vez que os dados do PNAD 2007 (IPEA, 2007), sobre crianças entre quatro e seis anos fora da escola, demonstram altos índices de exclusão: na Região Norte, $64,2 \%$; na Região Nordeste, $89,4 \%$; na Região Centro-Oeste, $67 \%$; na Região Sudeste, $80,9 \%$ e na Região Sul 66,4\%.

Nas ações voltadas à infanto-adolescência, destaca-se a capital do Rio Grande do Sul, com 14 citações e, em seguida, Palmas, com 13 citações. Surge, em primeiro lugar, uma capital do sul e em segundo uma do norte, contrariando a análise regional.

$\mathrm{Na}$ política de assistência social não há grande destaque, sendo tais ações citadas no máximo três vezes em algumas capitais, deixando de ser citada em outras. Por derradeiro, na área da saúde o grande destaque é o município de Porto Alegre, que dedi- ca em seu PPA até sete ações dedicadas à saúde especializada da criança, do adolescente e da gestante, prometendo, em seu PPA, cumprir as diretrizes constitucionais e estatutárias.

A seguir são analisadas, figura 1, as ações existentes nas regiões brasileiras no que tange à sua natureza de prevenção, proteção, promoção, e as consideradas emergenciais, redistributivas e construtoras de autonomia, segundo a classificação de Kauchakje (2007).

Inicialmente, no que tange às ações de prevenção ${ }^{1}$ previstas nos PPAs das regiões brasileiras analisadas, verifica-se o destaque para a Região Nordeste, que dedica um número muito superior de ações à prevenção que as demais regiões analisadas. A Região Centro-Oeste por outro lado, surge com um pequeno número de ações voltadas à prevenção, porém deve-se destacar que agrega na presente análise um número menor de estados que as demais (2) o que também interfere nos dados. As Regiões Norte, Sudeste e Sul apresentam resultados numericamente semelhantes nestas ações. Numa análise geral, entre regiões e municípios, constata-se que todos demonstram em seu planejamento preocupação no desenvolvimento de ações de prevenção.

O segundo grupo de colunas diz respeito às ações de proteção ${ }^{2}$ destacadas mais uma vez na Região Nordeste, mas presentes também em todas as capitais e regiões, analisadas em números aproximados às ações de prevenção.

O terceiro grupo de colunas faz a análise quantitativa das ações de promoção ${ }^{3}$, nesse aspecto os números apresentam diferenças em relação aos anteriores, com um número muito comparativamente

\section{Figura 1 - Ações de prevenção, proteção e promoção agrupadas por região}

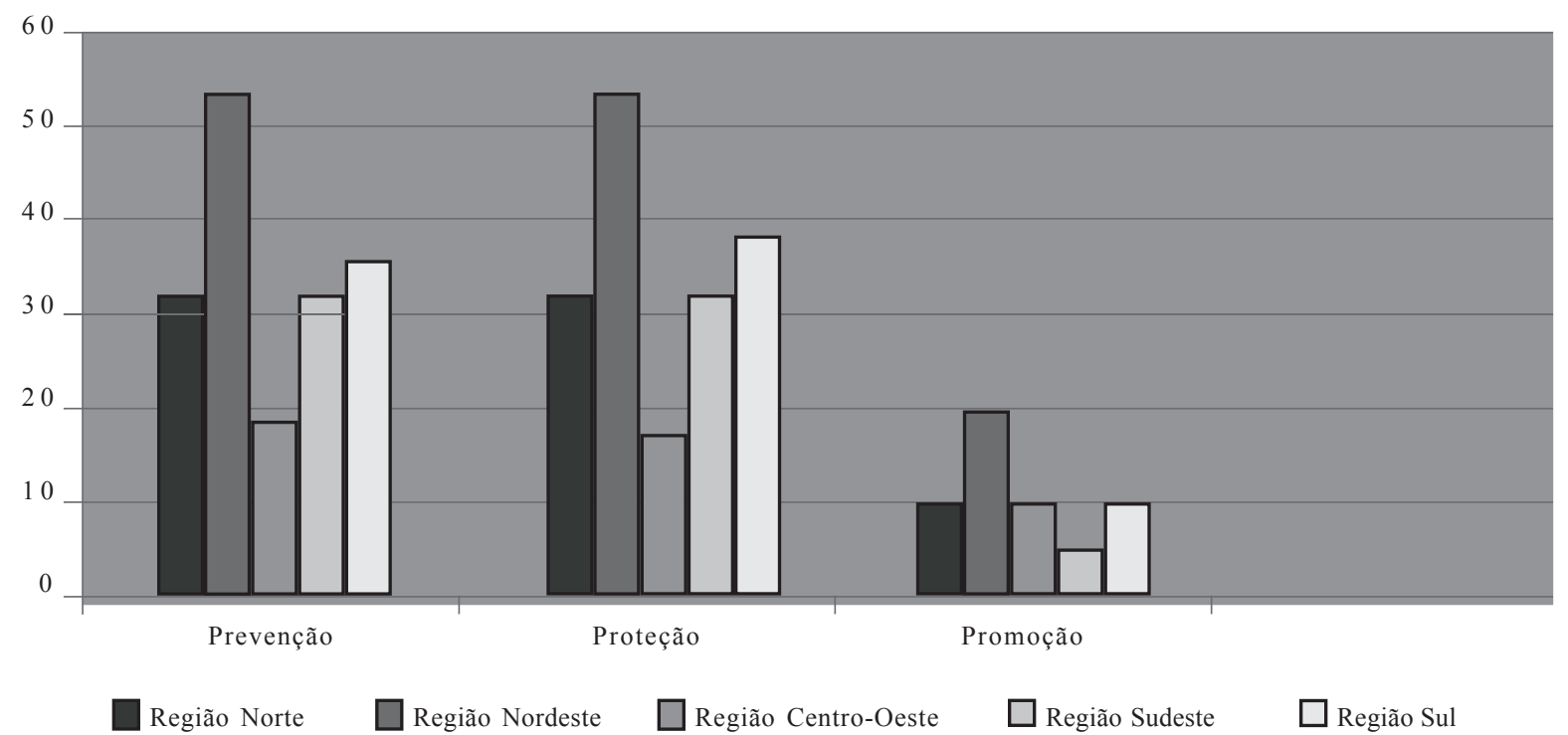

Fonte: elaboração das autoras. 
inferior em cada região e nas capitais. Enquanto na Região Nordeste as ações de prevenção aparecem 32 vezes nos PPAs, as ações de promoção surgem por dez vezes. Na Região Sudeste esta proporção cai de 32 de prevenção para quatro ações de promoção. Na Região Norte, Belém dedica no PPA apenas uma ação de promoção, já Boa Vista e Palmas dedicam quatro ações.

Sendo o desenvolvimento o aumento da capacidade de os indivíduos fazerem escolhas, é preciso definir o que é liberdade de escolha: a liberdade não é a ausência de restrições. Não se pode pensar a liberdade - e, portanto, o desenvolvimento - fora das condições concretas de seu exercício. Não basta que a lei garanta certos direitos, é essencial que os indivíduos tenham as capacidades, as qualidades, as prerrogativas de deslocar-se, de participar dos mercados e de estabelecer relações humanas que enriqueçam sua existência (COSTA, 2003). Logo, as ações de promoção são necessárias.

A figura 2 tem por finalidade comparar as ações de caráter emergencial, as redistributivas e as construtoras de autonomia nas regiões brasileiras.

Em primeiro lugar, observam-se as ações emergenciais $^{4}$, com destaque para Região Sudeste com 15 ações listadas nos PPAs, enquanto que as Regiões Sul, Norte, Nordeste e Centro-Oeste concentram dez, nove, nove e três ações, respectivamente. Já os municípios Belém, João Pessoa e Goiânia não citam no PPA nenhuma ação dessa natureza, enquanto os outros municípios citam um número menor de ações, em relação àquelas analisadas na figura 2. O fato de algumas capitais não preverem no PPA ações dessa natureza pode ou significar que tais ações já existam na cidade e, por isso, sua ausência no planejamento, ou a sua inexistência.

O segundo grupo de colunas diz respeito às ações redistributivas ${ }^{5}$ que surgem com maior frequência nas Regiões, Norte e Centro-Oeste (doze e sete vezes). Com menor frequência são citadas essas ações no Nordeste, no Sudeste e apenas duas vezes na Região Sul. Fechando a análise das capitais, verifica-se a presença dessas ações em todas elas, com exceção de São Luís.

O último bloco de colunas dispõe as ações construtoras de autonomia ${ }^{6}$ previstas na Região Nordeste por 13 vezes e na Região Norte por 11 vezes, verificadas com menor frequência nos PPAs das demais regiões (nove na Região Centro-Oeste, quatro na Sul e três na Sudeste). Com relação aos municípios, verifica-se a presença de ações dessa natureza em quase todos, com maior freqüência em Aracaju, Boa Vista e Brasília (cinco vezes), mas nenhuma vez na capital do Rio de Janeiro. Sobre as ações redistributivas e construtoras de autonomia percebe-se a necessidade das pessoas de serem vistas como ativamente envolvidas na conformação de seu próprio destino, e não apenas como beneficiárias passivas dos frutos de engenhosos programas de desenvolvimento. O Estado e a sociedade têm papéis amplos no fortalecimento e na proteção das capacidades humanas. São papéis de sustentação e não de entrega sob encomenda. A perspectiva de que a liberdade é central em relação aos fins e aos meios do desenvolvimento merece toda a atenção (COSTA, 2003). Não se pode esquecer que décadas de clientelismo consolidaram neste país uma cultura

\section{Figura 2 - Ações de caráter emergencial, as redistributivas e as construtoras de autonomia}

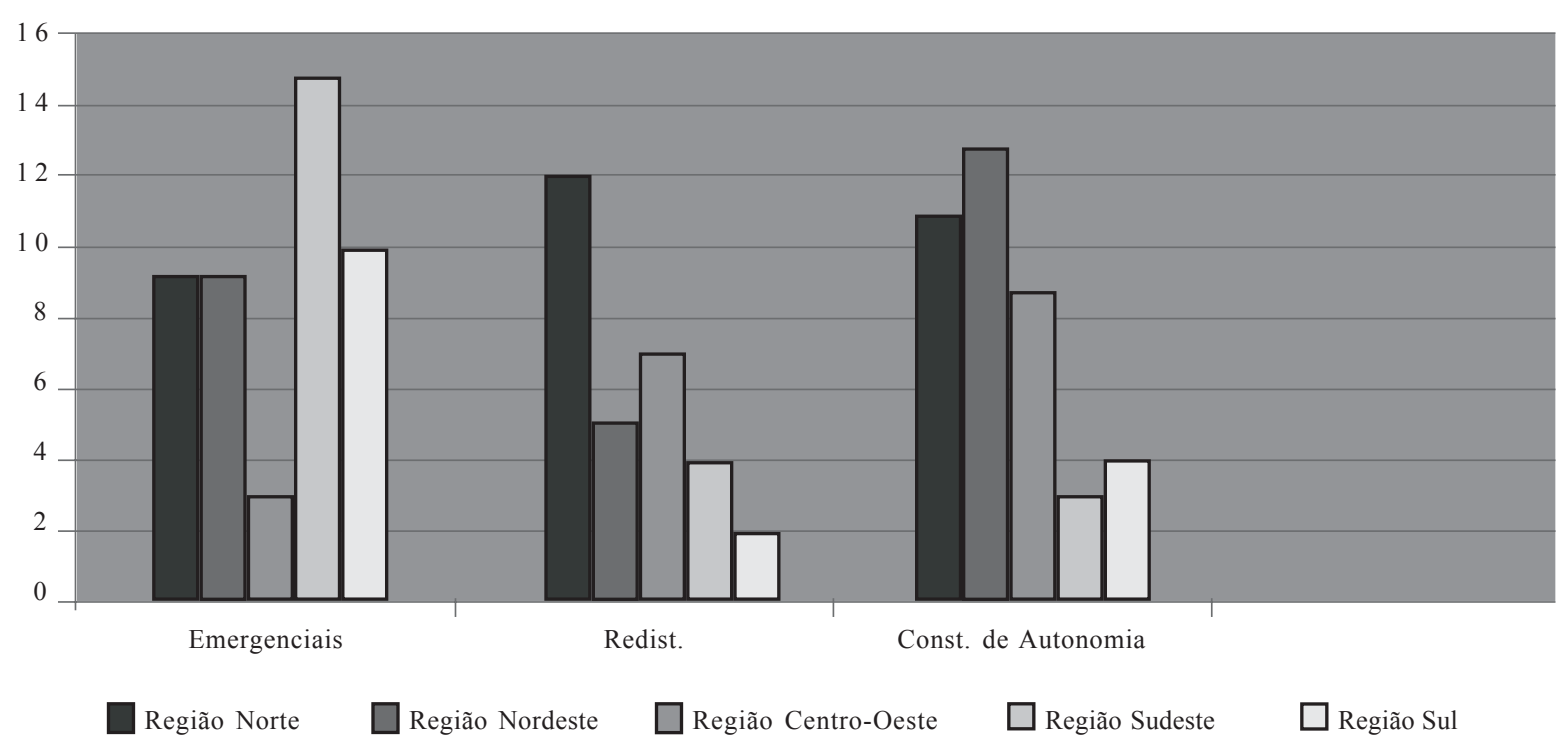

Fonte: elaboração das autoras 
tuteladora que não tem favorecido o protagonismo nem a emancipação dos usuários das políticas sociais, especialmente da Assistência Social (os mais pobres) (YASBEK, 2004).

Observa-se, no todo da análise realizada, uma consolidação da política de educação como competência municipal e o entendimento de sua priorização em todos os municípios estudados. Mesmo assim os índices demonstram que ainda existem muitas crianças e adolescentes fora dos bancos escolares. São 2,2 milhões de crianças e adolescentes que ingressaram na primeira série do ensino fundamental, mas não deverão finalizar a oitava série. O sistema Edudatabrasil, do Ministério da Educação, revela que pouco mais da metade das crianças $(53,8 \%)$ que entraram no ensino fundamental, em 2005, deverão concluir o ciclo.

Os municípios Curitiba e Porto Alegre merecem especial menção. O primeiro município por dedicar metas numericamente apresentadas no enfrentamento da problemática relacionada ao segmento objeto de estudo, e o segundo por desenvolver muitas ações municipais diversificadas em relação aos demais, demonstrando ações voltadas ao empreendedorismo e ao protagonismo juvenil. Posto isso, a região que acaba por se aproximar pelo conjunto de fatores observados do modelo ideal de planejamento voltado à criança e ao adolescente é a Região Sul. Como municípios mais distantes de cumprirem as premissas legais do ECA, destacam-se os municípios do Rio Branco (capital do Acre) por não mencionar a infância e juventude no PPA. A seguir está Porto Velho que citou uma ação e seis objetivos voltados ao segmento. Por fim vem São Luís que não dedica qualquer objetivo voltado a crianças e adolescentes, apresentando somente quatro ações, incluindo-se assim no rol das capitais pesquisadas mais distantes de cumprirem as exigências legais.

Como municípios mais próximos ao cumprimento do que dispõe o legislador sobre a proteção especial ao novo sujeito de direitos, criança e adolescente, destacam-se Palmas, Brasília, Vitória, Curitiba e Porto Alegre, entre as 19 capitais analisadas. Os fatores que levam esses municípios a receberem destaque neste enfoque é a quantidade e a qualidade de objetivos e ações previstos nos PPAs, mesclados a iniciativas do governo federal, estadual e municipal em relação às quatro políticas (assistência social, educação, saúde e proteção especial à infância e juventude).

\section{Considerações finais}

Chamam a atenção as diferentes formas de redação do Plano Plurianual que variam muito de município para município, ora citando objetivos, metas, equipamentos, órgãos executores e ações, ora apenas as ações planejadas. Enquanto alguns municípios dedicam páginas a objetivos, eixos norteadores, equipamentos e ações dirigidos à infanto-adolescência, outros sequer chegam a citar qualquer intenção voltada a esse segmento.

Ficou demonstrado que, pelo conjunto de documentos analisados, apesar da Constituição Federal ter determinado o processo de descentralização político-admnistrativa e municipalização, os municípios, no atendimento às políticas para a infância e juventude, acabam por repetir programas criados pelo governo federal ou estadual, deixando de criar ou explicitar programas municipais que deem conta de todas as demandas existentes e das peculiaridades locais. E apesar do ECA determinar a priorização do segmento, criando um sistema de garantias de direitos envolvendo diversos atores sociais, trabalhando harmoniosamente e cooperando mutuamente, pelo que se depreende de alguns documentos de planejamento, o sistema determinado em lei encontra-se em algumas localidades longe de sair do papel. Cita-se o exemplo da cidade do Rio Branco que não citou em seu PPA 2004-2007 qualquer objetivo, ações ou equipamentos voltados aos indivíduos estudados.

Assim sendo, observou-se que, dentro das limitações que o PPA admite, grande parte dos documentos não deixam transparecer a efetividade nas ações de promoção dos direitos fundamentais de crianças e adolescentes nos municípios brasileiros objeto de estudo. Mas essa não é a regra geral, alguns municípios exemplares já nominados desenvolveram objetivos, ações e equipamentos destinados à justa composição do Sistema de Garantia de Direitos. O ECA, em 13 de julho de 2008, completou sua maioridade. Nesses 18 anos de existência, houve muitos avanços, o que ficou demonstrado em algumas das capitais brasileiras analisadas que incorporaram seus princípios ao seu planejamento. Porém, num país com tantas diferenças e contrastes culturais, o gestor municipal deve estar atento para perceber as peculiaridades locais, adequando estratégias e ações adaptadas à realidade da infanto-adolescência, reconhecendo-os no lugar que merecem, como novos sujeitos de direitos.

\section{Referências}

BAPTISTA, M. V. Planejamento social: intencionalidade e instrumentação. São Paulo: Veras, 2003.

BRASIL. Estatuto da Criança e do Adolescente, Lei Federal n. 8.069/90, de 13 de julho de 1990, dispõe sobre a proteção integral à criança e ao adolescente. Brasília: Ministério da Justiça, 1995. 
BRASIL. Constituição da República Federativa do Brasil. Promulgada em 5 out. 1988. São Paulo: Atlas, 1999.

IPEA - Instituto de Pesquisa Econômica Aplicada. PNAD, 2007. Disponível em: < http://www.ipea.gov.br/sites/000/ $2 / \mathrm{c} \mathrm{o} \mathrm{m} \mathrm{u} \mathrm{n} \mathrm{i} \mathrm{c} \mathrm{a} \mathrm{d} \mathrm{o}-\mathrm{p}$ r e s i d e n c i a/ 08_10_07_Pnad_PrimeirasAnalises_N11demografia.pdf $>$. Acesso em: 15 maio 2008

COSTA, A. C. G. da. De menor a cidadão: notas para uma história do novo direito da infância e da juventude no Brasil. Brasília: Ministério da Ação Social, 2001.

COSTA, M. A. N. Synergy and Social Capital in the Construction of Social Policies: The Case of the Mangueira in Rio de Janeiro. Rev. Sociol. Polit., Curitiba,n. 21, 2003. Disponível em: <http://www.scielo.br/ scielo.php?script=sci_arttext\&pid=S010444782003000200010\&lng=en\&nrm=iso $>$. Acesso em: jun. 2008.

DOWBOR, L. Redes de apoio ao desenvolvimento local. (2006). Disponível em: <http://www.ritla.net/ index.php?option $=$ com_content\&task $=$ view\&id $=225 \&$ Itemid $=$ 131->. Acesso em: 15 abr. 2008.

KAUCHAKJE, S. Gestão pública de serviços sociais. Curtiba: IBEPX, 2007.

LOBATO, L. Aula: políticas e perspectivas de proteção social. Publicado em 2005. Disponível em: <http:// www.enap.gov.br/downloads/ec43ea4fglossario_Lenaura _Lobato.pdf.>. Acesso em: 11 jan. 2008.

MACEDO, R. C. M. O adolescente infrator e a imputabilidade penal. Curitiba: Lúmen Júris, 2008.

MAGALHÃES, S. M. de O.; BARBOSA, I. G. Do topo de uma montanha temos um ótimo ângulo de visão das coisas... Estudo e Pesquisas em Psicologia, UERJ, v. 5, n. 1, 2005. Disponível em: <http://www.revispsi.uerj.br/v5n1/ artigos/a03.pdf $>$. Acesso em: jan. 2008.

MENDEZ, E. G. O novo Estatuto da Criança e do Adolescente - uma visão latino-americana. Brasília: UnB, 1991.

MINAYO, M. C. de S. O desafio do conhecimento. São Paulo: Hucitec, 1993.

PIOVESAN, F. Mecanismos Internacionais e construção de um sistema nacional de proteção dos direitos humanos. Comissão de Cidadania e de Direitos Humanos da Assembléia Legislativa do Rio Grande do Sul. Relatório Azul, edição comemorativo de 10 anos, Porto Alegre: Corag, 2004. p. 362-369.
PONTES JÚNIOR, F. Conselho de direitos da criança e do adolescente. São Paulo: Malheiros, 1993.

REZENDE, D. A. Planejamento estratégico municipal como proposta de desenvolvimento local e regional de um município paranaense. Revista da FAE, v. 9, p. 87-104, 2006.

SANTIAGO, L. B. et al. Incentivo ao aleitamento materno: a importância do pediatra com treinamento específico. Arch. Pediatr. Urug. [online]. v. 76, n.1, p.75-84, mayo 2005. Disponível em: <http://www.scielo.edu.uy/ scielo.php?script $=$ sci_arttext \&pid=S $0004-$ $05842005000100015 \& \operatorname{lng}=\mathrm{es} \& \mathrm{nrm}=\mathrm{iso}>$. Acesso: em jun. 2008.

SANTOS, E. A. dos. Criança e adolescente sujeitos de Direito. Revista IBCT. Disponível em: <http:// revista.ibict.br/inclusao/index.php/inclusao/article/view/ 56/78>. Acesso em: 9 jul. 2008.

SEDA, E. A proteção integral: um relato sobre o cumprimento do novo direito da criança e do adolescente na América Latina. São Paulo: Ades, 1995.

VERONESE, J. R. P.; RODRIGUES, W. M. A figura da criança e do adolescente no contexto social: de vítimas a autores de ato infracional. Brasília: ABMP, 2001.

YASBEK, M. C. O programa fome zero no contexto das políticas sociais brasileiras. São Paulo Perspec, v. 18, n. 2, 2004. Disponível em: <http://www.scielo.br/ scielo.php?script=sci_arttext \&pid=S $0102-$ $88392004000200011 \& \operatorname{lng}=\mathrm{en}^{\mathrm{a}} \mathrm{nnm}=\mathrm{iso}>$. Acesso em: jun. 2008.

\section{Notas}

1 Ações de prevenção são projetos que previnem situações de vulnerabilidade e risco, por meio de: monitoramento das situações que as possam gerar, desenvolvendo potencialidades e aquisições; fortalecimento de vínculos familiares e comunitários; inclusão nas políticas sociais, programas e projetos existentes (KAUCHAKJE, 2007).

2 Ações de proteção envolvem projetos destinados às pessoas e à populações em situação de vulnerabilidade e risco. Garantem: aquisições materiais (renda, alimentação, habitação entre outros); aquisições imateriais (apropriação cultural/ educacional e de capacidades como capacitação profissional, por exemplo); acolhida e prestação de serviços que retirem da situação de vulnerabilidade e risco (por exemplo, de uma exposição à violência ou exploração) (Ibid.).

3 Ações de promoção são projetos que fornecem condições para que pessoas, grupos sociais e coletividades saiam e permaneçam fora de situações de exclusão social, propiciando: desenvolvimento da autonomia /projetos de 
vida alternativos, eliminação das relações que provocam dependência e subordinação (Ibid.).

4 Ações emergenciais visam o atendimento imediato das situações de risco pessoal e social pela violação de direitos (vinculada à negligência, ao abandono e à violência) ou, ainda, por fatores naturais, como abrigamento com apoio psicossocial, provimento de alimentos, vestuário, medicação (Ibid.).

5 Ações redistributivas dirigem-se para a distribuição indireta de bens e recursos socioeconômicos pela mediação das políticas sociais, como formas de transferência de renda, crédito popular e benefícios (Ibid.).

6 Ações de construção de autonomia prevêem a superação das situações de subalternidade e de estigmatização vinculadas à exclusão socioeconômica e sociocultural, isto é, ao empobrecimento, desemprego, à discriminação etnicocultural, pelo gênero, necessidade especial, ciclo de vida. Promovem capacitação profissional através de geração de emprego, trabalho e renda, cooperativismo e associativismo, economia solidária, formação juvenil, fortalecimento de ações organizativas de enfrentamento à pobreza, monitorame nto de riscos e vulnerabilidades sociais (Ibid.).

\section{Jimena Cristina Gomes Aranda Oliva}

Mestre em Gestão Urbana pela Pontifícia Universidade Católica do Paraná (PUC-PR)

Bacharel em Direito pela Universidade Católica de Direito de Santos

Professora de Direito da PUC-PR

\section{Samira Kauchakje}

Pós-Doutorado pela Universidade Federal do Rio de Janeiro (UFRJ)

Doutorado em Educação pela Universidade Estadual de Campinas (Unicamp)

Professora do Programa de Mestrado em Gestão Urbana na Pontifícia Universidade Católica do Paraná (PUC-PR)

\section{Curso de Direito da PUC-PR}

Rua Imaculada Conceição, 1155

Bloco III do Parque Tecnológico

Prado Velho

CEP: 80215-901

Curitiba - Paraná 